\title{
Design Analysis of Compact Autonomous Railway Inspection Vehicle (CARIV)
}

\author{
Mohd Bazli Bahar, Mohd Shahrieel Mohd Aras, Lim Zhi Han, Ho Gui Yan, Teo Seng Loong, \\ Marizan Sulaiman, Fadilah Ab Azis
}

\begin{abstract}
The aim of this project is to reduce the occurrence of train derailment due to railway track defects to zero in the following years by increasing the efficiency of railway track inspection and railway track defects detection. Moreover, this project aims to reduce the need of railway track inspection workers to perform on-foot inspection at odd hours. All of these can be achieved by deploying the compact autonomous railway inspection vehicle (CARIV). The CARIV is equipped with ultrasonic sensors, which will be used to detect railway track defects. In addition, when railway track defects are detected, CARIV will take an image of the defective section of the railway track and send to the operator together with the GPS coordinates via email. CARIV will also be providing live video feedback to a browser so that the operator is able to perform visual checking for railway track defects undetectable by the ultrasonic sensor without having to perform on-foot inspection. This is to allow the operator to inspect the railway track defect in detail to determine the seriousness of the railway track damage. The final phase of this project is to test the system on fabricated railway track with defects.
\end{abstract}

Keywords: CARIV, Fritzing, SolidWorks, track defect.

\section{INTRODUCTION}

In Malaysia, railway transportation consists of heavy rail, commuter rail, monorail, light rapid transit (LRT), mass rapid transit (MRT), airport rail link and a funicular railway line [1]. In Peninsular Malaysia, the railway network covers most of the 11 states whereas in East Malaysia, only Sabah has railways. Heavy rail is mostly used for freight transport purposes while commuter rail is usually used for inter-city and intra-city passenger transportation. Meanwhile, the other railways are normally used for intra-city urban public transportation. Keretapi Tanah Melayu Berhad (KTMB) is the largest railway operator in Malaysia as their railway track length is up to 2,330 km while Rapid Rail Sdn Bhd has railway track length up to $151.1 \mathrm{~km}$ [2]. Moreover, Greater Kuala Lumpur/Klang Valley has an average daily rail ridership of 694,057 passengers in 2017 [3].

In order to ensure that the railway transportation service operate smoothly, rolling stock and railway track maintenance must be performed regularly. Example of railway track problems that may occur are shelling, cracks, squats, and broken end rail as in Fig. 1-4 [4]. Hence, railway inspection workers must perform inspection frequently to

Revised Manuscript Received on September 14, 2019.

Mohd Bazli Bahar, Mechatronics Department, Universiti Teknikal Malaysia Melaka, Malaysia.( Email: bazli@utem.edu.my)

Mohd Shahrieel Mohd Aras, Mechatronics Department, Universiti Teknikal Malaysia Melaka, Malaysia. (Email: shahrieel@utem.edu.my)

Marizan Sulaiman, Mechatronics Department, Universiti Teknikal Malaysia Melaka, Malaysia. (Email: marizan@utem.edu.my)

Fadilah Ab Azis, Electrical Department, Universiti Teknikal Malaysia Melaka, Malaysia.( Email: fadilah@utem.edu.my)

Lim Zhi Han, Ho Gui Yan, Teo Seng Loong, Mechatronics Department, Universiti Teknikal Malaysia Melaka, Malaysia avoid service disruption or accidents due to railway track problems [5], [6]. However, due to the fact that railway transportation operates during daytime and night time, railway inspection workers are forced to perform on-foot inspection at odd hours which is usually after midnight and with limited time to inspect thoroughly. Based on track safety standards by United States Department of Transportation, railway track inspection must be performed at least once a week [7]. In railway transport, the spacing of the rails on a railway track is known as track gauge where it is measured between the inner faces of the load bearing rails [8].

To overcome this issue, recent research give emphasis on vision base system either integrated it with some artificial intelligence [6], [5], [9] or just the basic machine vision system [10]-[12]. Various image processing and classifiers method introduce such as maximally stable extremal region (MSER) technique [13] three-dimensional (3D) Digital Image Correlation (DIC) systems [9], and edge and feature extraction methods [12] to get the right decision in evaluating the rail track condition. Additional sensory was also discuss to increase the accuracy of the image capture such as IMU unit in order to reduce the blurring image [14]. However, most of the research are focus on image processing which test was done using a set of image samples [13], [6]. This also bring to lack of suitable method discuss on real time monitoring such done in [14], [9].

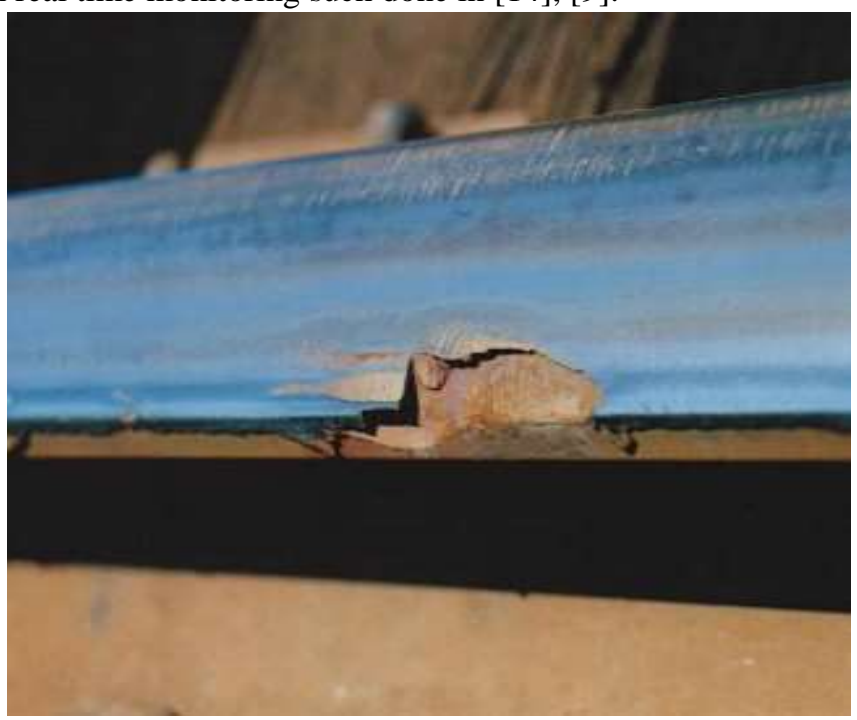

Fig. 1. Shelling 


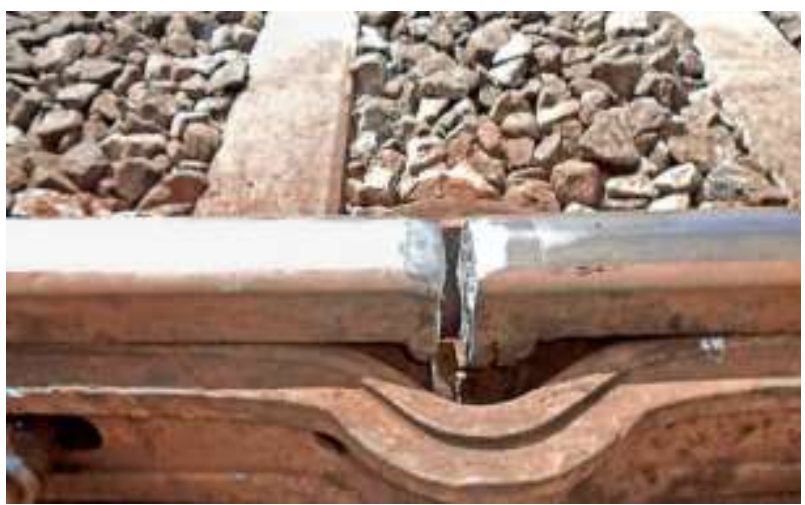

Fig. 2. Crack

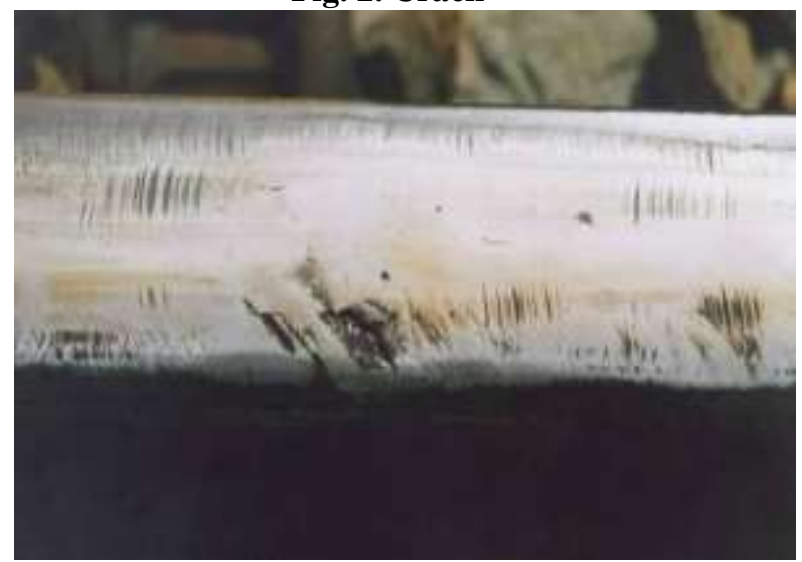

Fig. 3. Squats

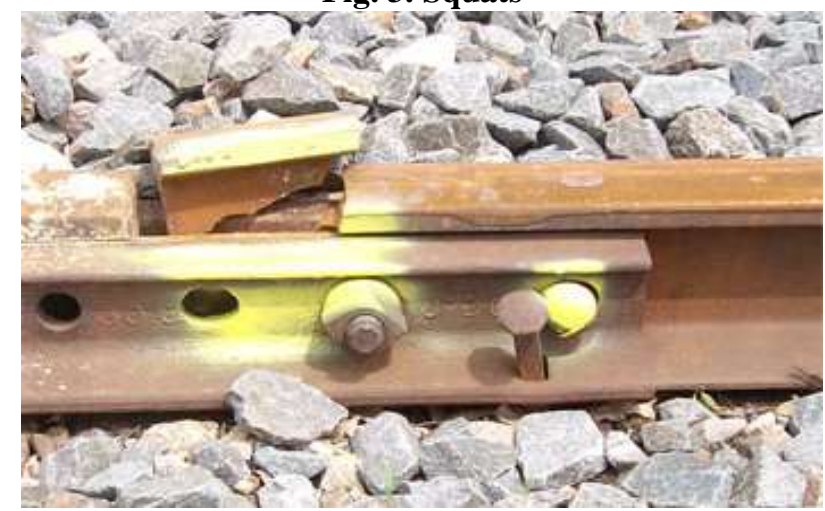

Fig. 4. Broken end rail

In recent years, the frequency of service disruptions, especially KTMB train service has increased significantly. Between 2016 and the first quarter of 2018, KTMB train service had 23 service disruptions where 6 of them were due to train derailment [15]. The main cause of train derailment is mechanical failure of a track component such as the example of railway track problems stated. In addition, due to the lack of railway track inspection is one of the reasons why the frequency of service disruptions is increasing. So, a more effective and time-efficient railway track inspector is needed.

The objectives of this project are to increase the efficiency of railway track defects inspection and reduce the time taken for railway track inspection and railway track defects detection. In addition, reducing the need of railway track inspection workers to perform on-foot inspection at odd hours. Ultimately, decrease the occurrence of train derailment due to railway track defects to zero in the following years.

\section{METHODOLOGY}

\section{A Mechanical Systems}

The mechanical systems consist of the body, telescopic cylinder, wheel, battery housing and electronics housing. All of these parts will be designed using SolidWorks to ensure that it is compact and modular. In order to make it compact, the body of CARIV is designed to be retractable and extendable with the telescopic cylinder attached. Since CARIV is designed to travel on railway tracks, the design of the wheel is based on rail wheels. In addition, most rail wheels have a conical geometry to keep the train's motion aligned with the track. In order to keep the wheels and train running on the rail tracks when limits of the geometry-based alignment are reached, rail wheels have a flange on one side.

Furthermore, the battery housing is designed to be the power provider of the mobile robot that contains batteries, voltage regulators with display and rocker switch. Moreover, it is important to design the battery housing such that the display of the voltage regulators can be easily monitored. The electronics housing is required to contain the single-board computer, microcontroller, sensors and other electronic components. Hence, it is the most important component on the mobile robot. In addition, the design must ensure that the electronic components are enclosed so that the components will be not affected by environmental factors.

SolidWorks evaluation tools such as interference detection, clearance verification, hole alignment and collision detection can be used to analyse and simulate all of the designs. This is to ensure that the design is error free. Moreover, SolidWorks Simulation can be used to perform on parts that required stress, displacement and strain simulation with external force or torque. SolidWorks Flow Simulation can also be used to test the aerodynamic of the design. SolidWorks Composer is used to present the final design.

Rapid prototyping with 3-dimensional printer will be used to create the body, telescopic cylinder, wheel, battery housing and electronics housing with polylactic acid (PLA) material. This is to ensure that CARIV is lightweight so that it can be easily carried by hand since SolidWorks can inform the mass of material used. However, each part will have multiple sub-parts that can be assembled together due to the dimension restriction of the 3-dimensional printer.

\section{B Electrical \& Electronics Systems}

Ultrasonic testing uses ultrasound, which are high frequency sound that are above the range of human hearing to measure geometric and physical properties of materials. Ultrasonic testing is a non-destructive testing (NDT) method, which is the most extensively used method in detecting railway track defects due to its advantages such as safe, gives instant results and can detect the majority types of defects [15]. In addition, it is sensitive to both surface and subsurface discontinuities. For surface discontinuities, trigger and echo method will be used, where the ultrasonic sensor will be placed parallel to the railway track and at a

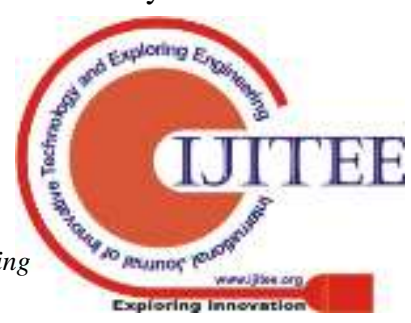


constant distance. So, when the distance detected is not same as the constant distance, then there is a railway track defect. Furthermore, ultrasonic inspection of railway is

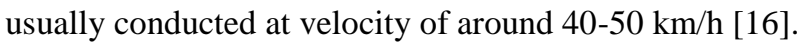

The motor that will be used for the compact autonomous railway inspection vehicle is a type of DC geared motor with encoder, where a quadrature Hall Effect encoder board is designed to fit on the rear shaft of the motor. Moreover, GPS module can be used to obtain coordinates of the defective railway track. CARIV's electrical systems provide the mobile robot with power and an interface between the computer and the other electronic components. A power system is designed using Fritzing software to simulate the power distribution of the mobile robot. In addition, an electronics interface that consists of serial communication, general purpose input output (GPIO) communication and sensor interface is also design using Fritzing software.

Microcontrollers and single-board computers have multiple GPIO pins to read analog and digital inputs from sensors as well as output analog and digital voltage signals. It is to response to the constantly changing electrical needs of the mobile robot. Microcontroller is used to read measurements from the ultrasonic sensors that output digital signals and receive digital inputs. Moreover, single-board computer is used to receive GPS coordinates from the GPS Module through Universal Asynchronous Receiver and Transmitter (UART) communication. In addition, singleboard computer is also used to obtain railway track defect images and railway track video recording from cameras through serial communication protocol. The program for the microcontroller and single-board computer will be written in $\mathrm{C}$ and Python.

\section{RESULTS AND DISCUSSION}

CARIV's body provides protection for the motors, battery housing and electronics housing from the environment. The body also requires sockets for the telescopic cylinder to be inserted. In addition, the base of the body has sockets for the motor and electronics housing. There are also holes for the wheels, ultrasonic sensors and camera so that the base will not obstruct the components. The body has an aerodynamic shape and dimension of $440 \mathrm{~m}$ long by $200 \mathrm{~m}$ wide by $160 \mathrm{~mm}$ tall.

In addition, air flow is simulated flowing towards the front part of the body to prove that the design of the body has an aerodynamic feature (see Fig. 7).

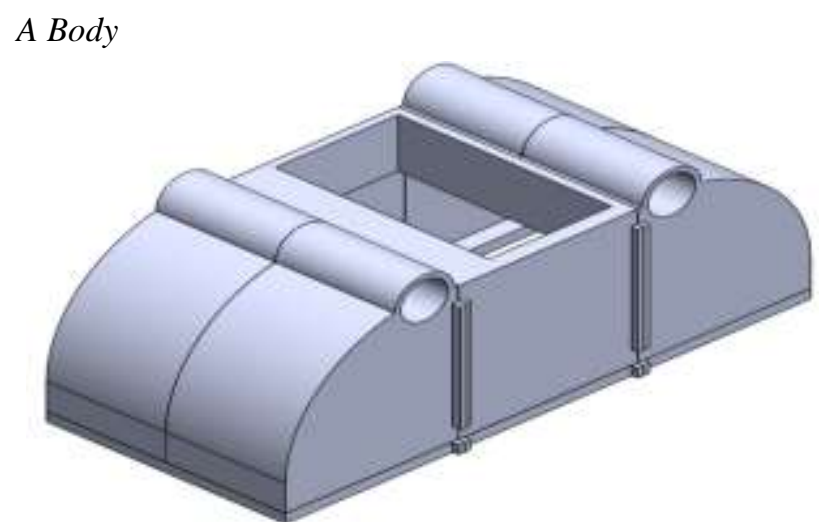

Fig. 5. Design of body

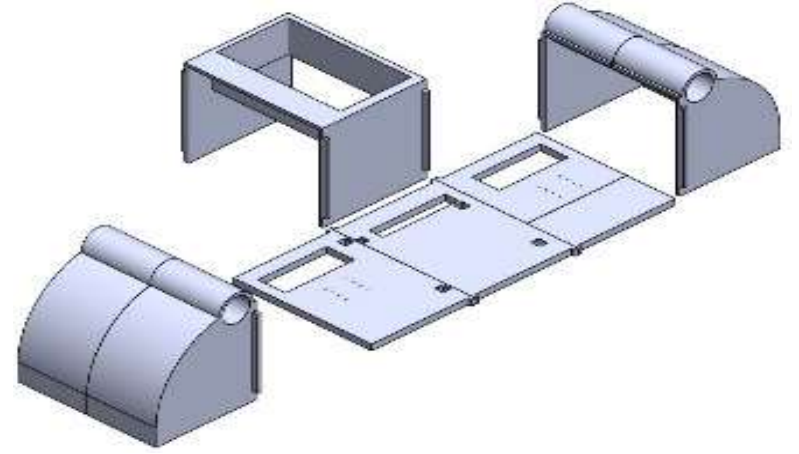

Fig. 6. Exploded view of body

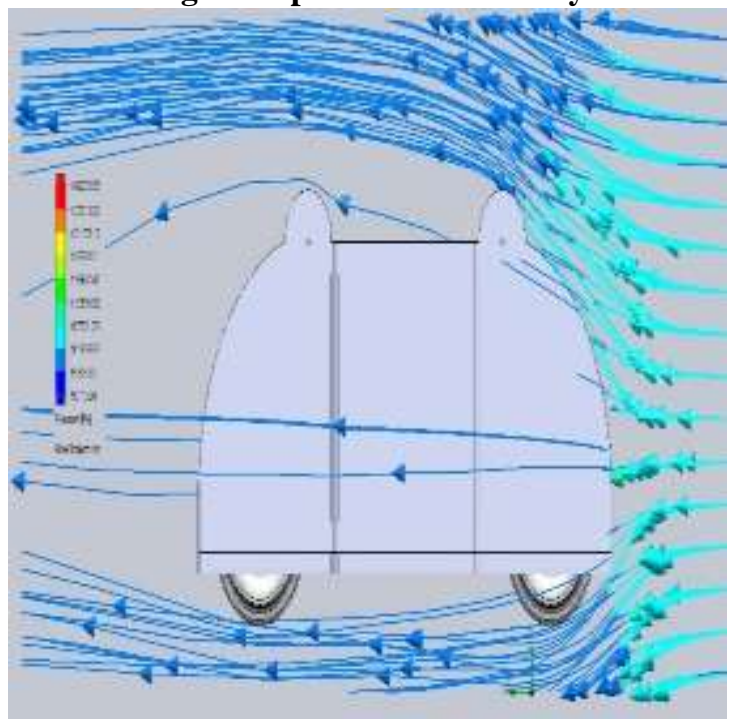

Fig. 7. Flow simulation of body

Telescopic Cylinder

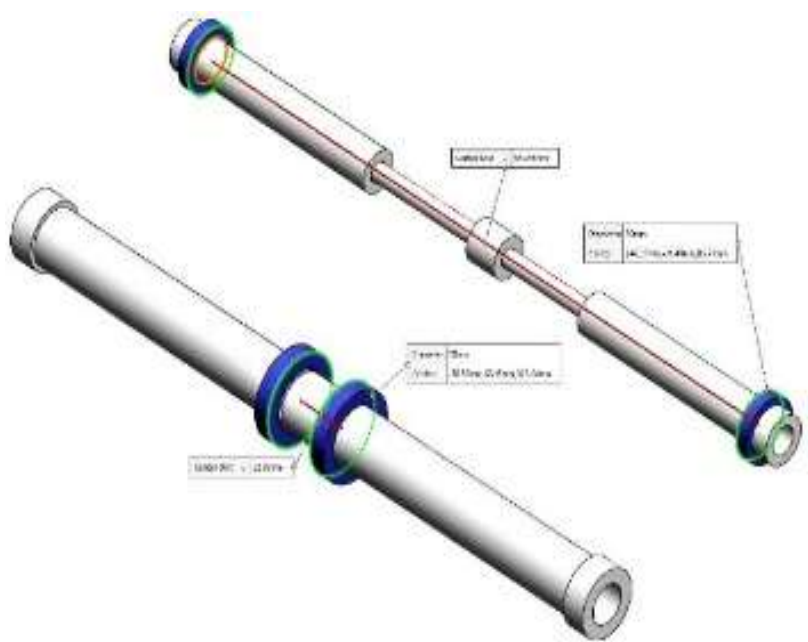

Fig. 8. Design of telescopic cylinder

CARIV has to be compact during operation and inactivity. So, a telescopic cylinder is designed to fit that characteristic and it act as the connector for the two bodies. Thus, CARIV is able to extend to fit the width of the rail way track and retract for ease of transfer and storage. The telescopic cylinder has a minimum length of $32.82 \mathrm{~mm}$ and a maximum length of $589.58 \mathrm{~mm}$ (see Fig. 17). However, the length of telescopic cylinder will be locked at $500 \mathrm{~mm}$ during operation as the railway track gauge designed has a width of $500 \mathrm{~mm}$. 


\section{$B$ Wheel}

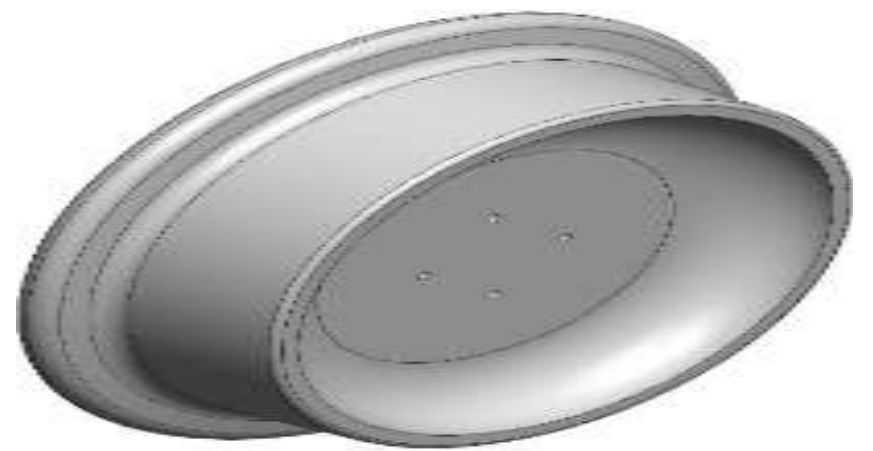

Fig. 9. Design of rail wheel

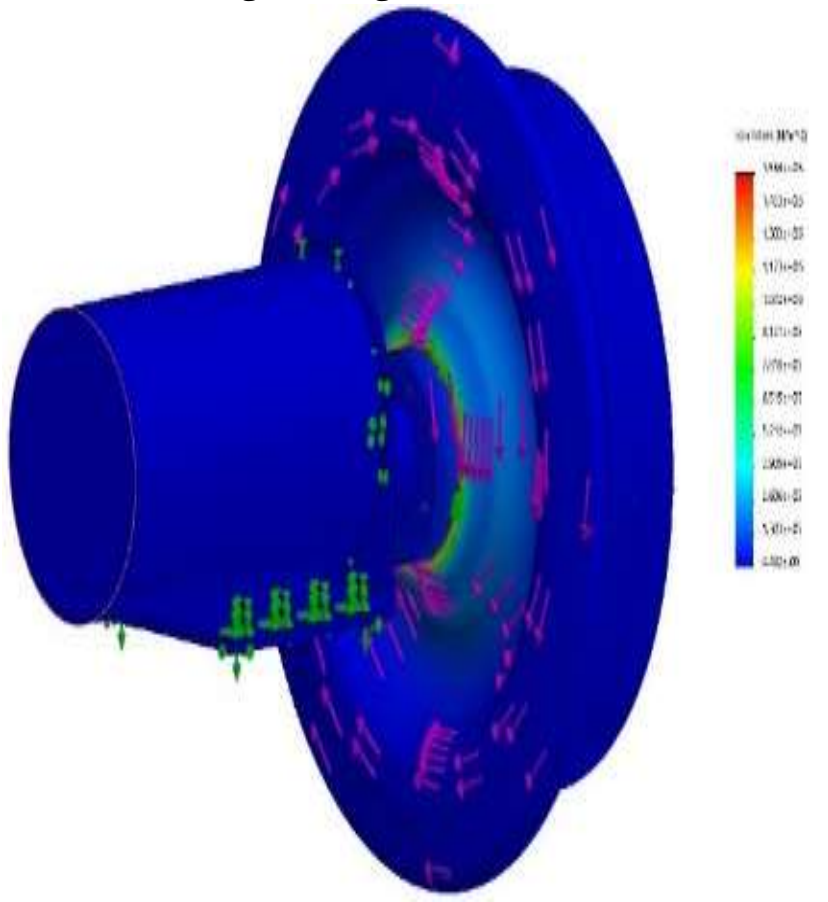

Fig. 10. Stress simulation of rail wheel

Thus, CARIV's rail wheel will have similar characteristics as train rail wheel (see Fig. 9.). The flange diameter of the wheel is $100 \mathrm{~mm}$ while the diameter of the conical geometry of the wheel starts from $83.66 \mathrm{~mm}$ and has a slope of $0.087 \mathrm{~mm} / \mathrm{mm}$ over a length of $19 \mathrm{~mm}$.

The motor that is used has a rated load torque of $0.128 \mathrm{Nm}$. Hence, the motor is fixed while a torque of $0.128 \mathrm{Nm}$ is applied to the wheel and the result of the stress simulation is obtained (see Fig. 10.). It is observed that the area where the wheel is attached to the motor shaft has the highest stress but there is no deformation that occurred.

\section{Battery Housing}

The battery housing is the power provider of the mobile robot that contains lithium polymer batteries. In addition, the battery housing also consists of voltage regulators with display and rocker switch. So, it is important to design the battery housing such that the display of the voltage regulators can be easily monitored. Also, the rocker switch is positioned at a location that can be easily seen and pressed. Since the base of the body is a rectangular cuboid, it is decided that the shape of the battery housing will be a rectangular cuboid as well (see Fig. 11). Battery housing has a dimension of $171 \mathrm{~mm}$ long by $100 \mathrm{~mm}$ wide by $60 \mathrm{~mm}$ tall and there is an opening above the voltage regulator.

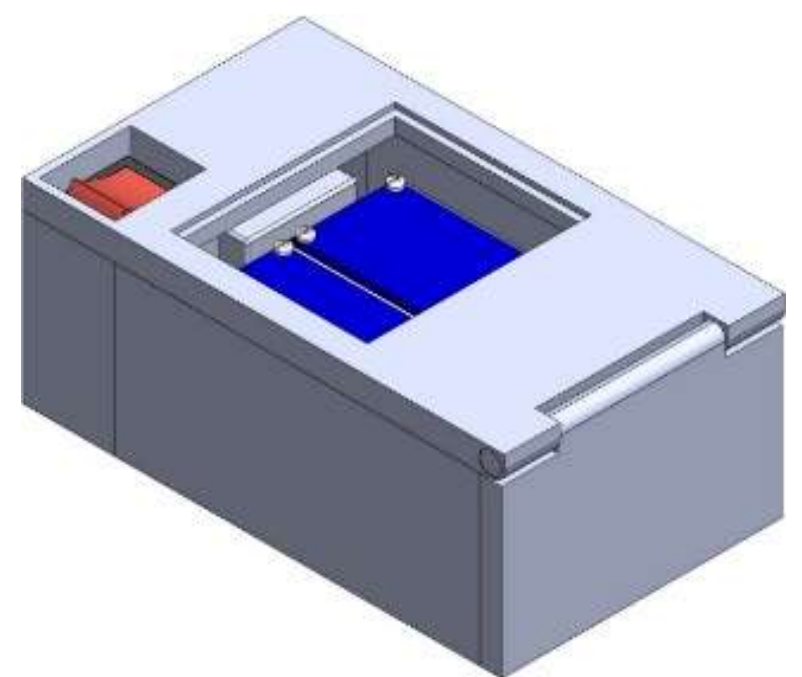

Fig. 11. Design of battery housing

Moreover, the front cover of the battery housing is connected to a rod that allows it to be opened and closed for battery substitution. Two DC Female Barrel Jacks are located at the bottom of the back-right corner, which is next to the rocker switch (see Fig. 12).

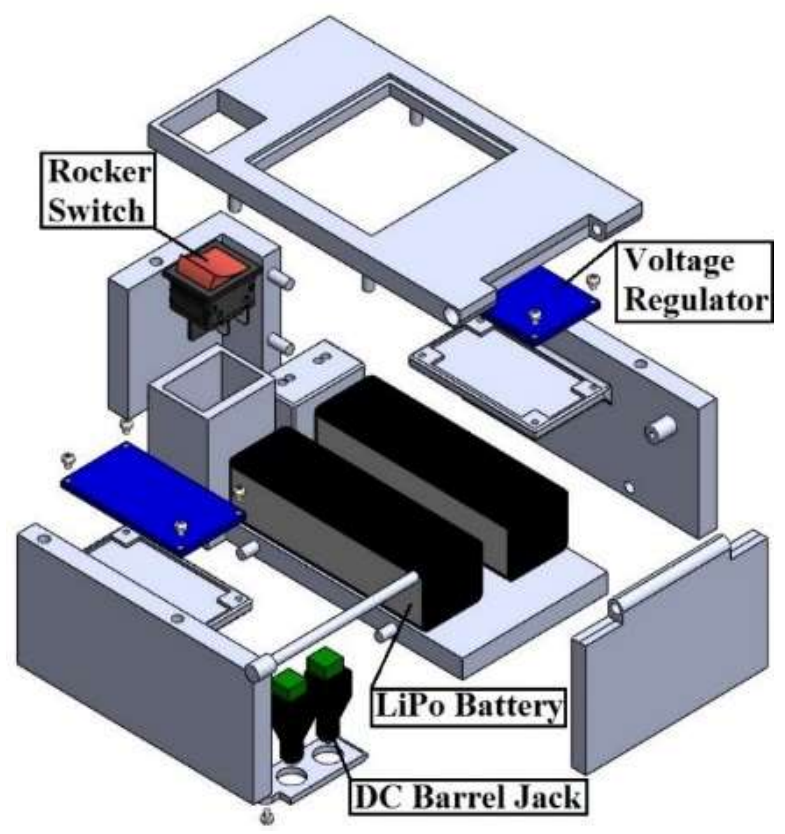

Fig. 12. Exploded view of battery housing

The mass of battery housing with all the components inserted is approximately 500 grams.

\section{Electronics Housing}

The electronics housing contains the single-board computer, microcontroller, sensors and other electronic components. Hence, it is the most important component on the mobile robot. In addition, the design must ensure that the electronic components are enclosed so that the components will be not affected by environmental factors. It is also decided that the electronics housing will have a rectangular cuboid shape with a dimension of $173 \mathrm{~mm}$ long by $160 \mathrm{~mm}$ wide by $79 \mathrm{~mm}$ tall (see Fig. 13).

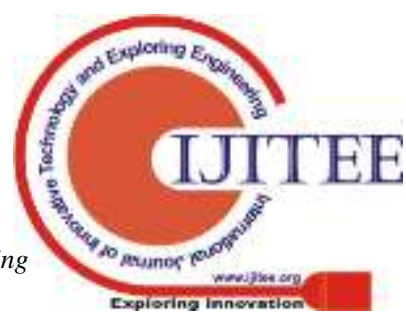




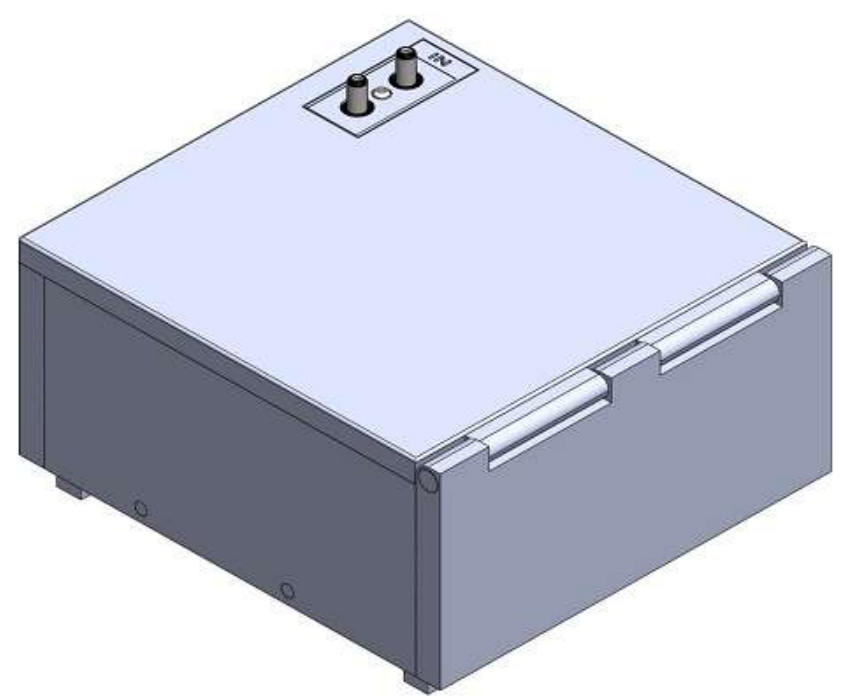

Fig. 13. Design of electronics housing

Similarly, the top cover of the electronics housing is connected to a rod that allows it to be opened and closed for electronic components inspection or replacement. Also, there are two DC Male Barrel Jacks at the top of the backright corner (see Fig. 14). So, when the top cover is closed, the battery housing can be placed on top of the electronics housing with the DC Barrel Jack plugged in.

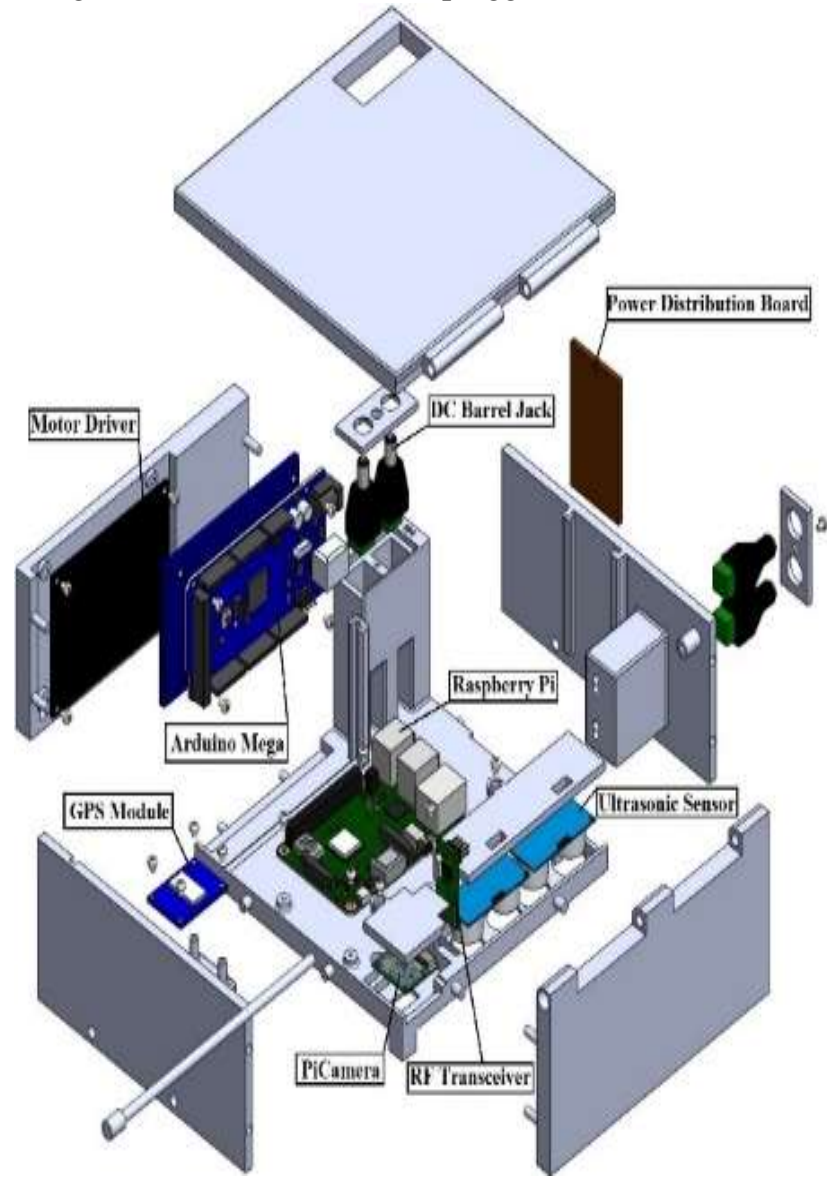

Fig. 14. Exploded view of electronics housing

The bottom part is fixed and a force of 4.9 Newton was applied to the top cover and the result of the simulation is obtained (see Fig. 15). It can be observed that the top cover is able to withstand the force where most of the area does not exceed half of the von Mises Stress.

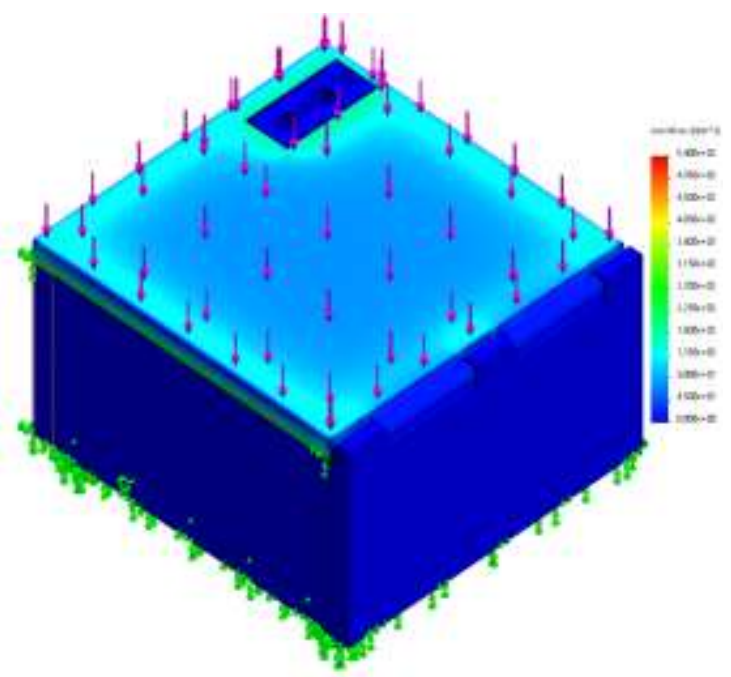

Fig. 15. Stress simulation of electronics housing

\section{E Power System}

Power for the entire mobile robot is provided by four Wild Scorpion lithium polymer (LiPo) batteries where each battery has a capacity of $2200 \mathrm{mAh}$, fully-charged voltage of $12.6 \mathrm{~V}$ and discharge rate of $30 \mathrm{C}$. So, this gives the vehicle a run time of about two to three hours, depending on the speed of the motors. In addition, each battery is regulated by a LM2596 DC-DC Adjustable Step-Down Voltage Regulator Power Supply Module with Display to maintain a constant and stable output voltage level for the electronic components. Moreover, it is built with digital display that enables voltage monitoring to prevent the LiPo batteries from over-discharge. For one set of battery box, it consists of two LiPo batteries where all the incoming power to the circuit box is routed to the power distribution board where one LiPo battery is dedicated to the motors while the other to the electronic components. Power distribution board provides regulated voltage rails at $+5 \mathrm{~V}$ and $+12 \mathrm{~V}$ to CARIV (see Fig. 16).

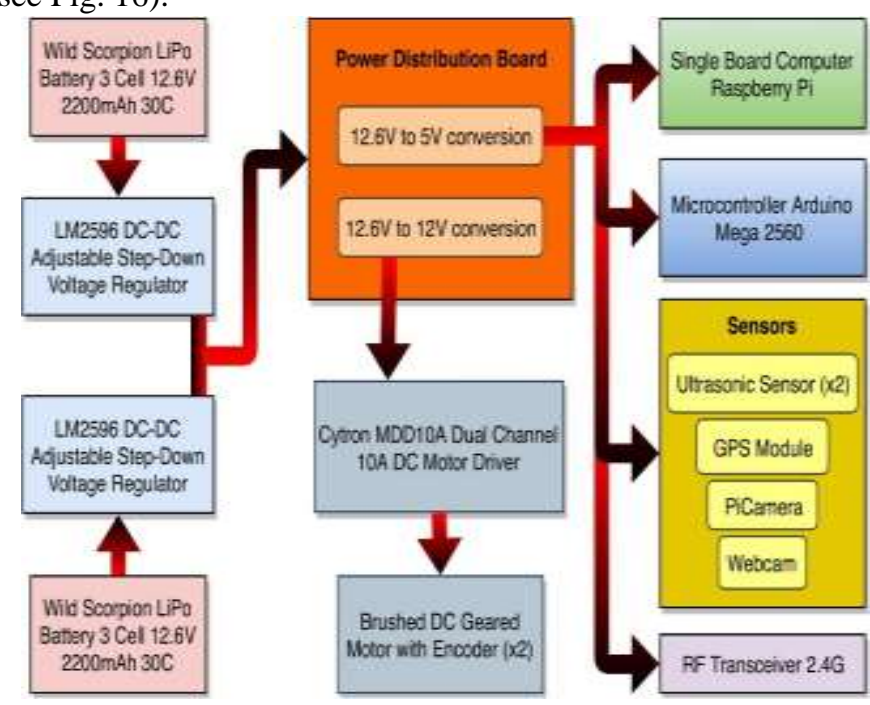

Fig. 16. Block diagram of CARIV's electrical system 


\section{Electronics Interface}

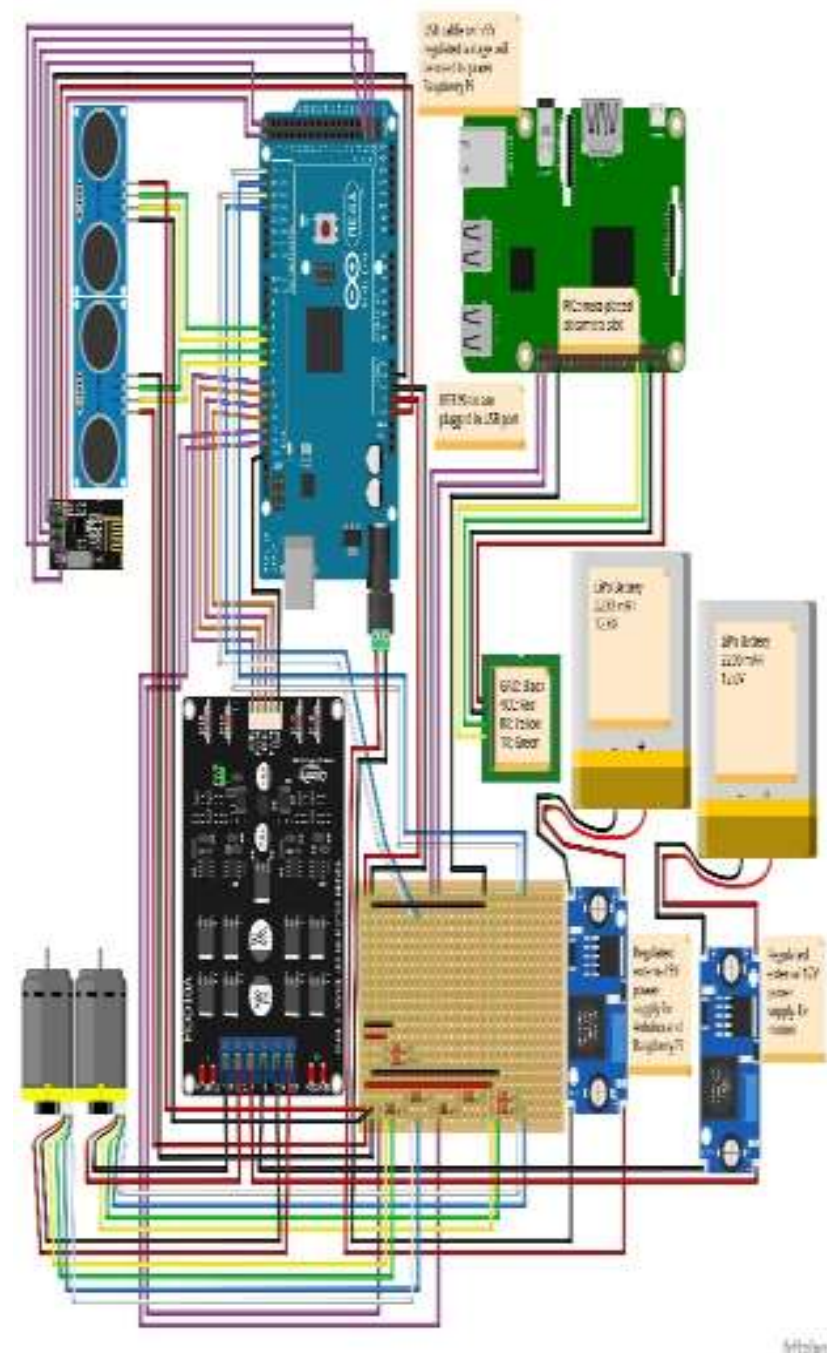

Fig. 17. Circuit of CARIV

Raspberry Pi is connected to Arduino Mega through a USB Type B cable and communicates with each other via serial communication interface. This enables the Raspberry Pi to be able to control and program the Arduino Mega from the Raspberry Pi. In addition, Raspberry Pi is also able to take and display incoming serial data through Arduino IDE for data analysis. This interface was chosen because it is noise-tolerant and universal. Raspberry Pi is also connected with Arduino Mega through jumper wires and communicates with each other via GPIO communication. This method of communication is executed by setting the GPIO to either high or low where it is integrated with conditional statements to perform desired commands.

The HC-SR04 ultrasonic sensor offers excellent range accuracy and adequately stable readings at a very low cost. It uses two digital GPIO pins, which is an output pin and input pin to interface with Arduino Mega. Moreover, the ranging distance is from $2 \mathrm{~cm}$ to $400 \mathrm{~cm}$ with a resolution up to $0.3 \mathrm{~cm}$. Two HC-SR04 ultrasonic sensors are used to obtain an average reading and to ensure that railway track defect is always detected

GY-NEO6MV2 is a low cost and powerful GPS receiver that uses the famous and high-end u-Blox Neo-6M GPS Module. In addition, there is a built-in EEPROM and an external ceramic antenna that is connected to the board via U. FL connector to offer better signal reception. The communication interface of this GPS module with the Raspberry Pi is through UART communication at 9600 baud rate per second. Thus, CARIV can obtain accurate coordinate readings at high refresh rate.

CARIV uses 5 Megapixel (MP) PiCamera and Logitech Webcam to capture image of defective railway track and to stream live video feedback of railway track respectively. The PiCamera is a custom designed add-on for Raspberry Pi which has a fixed focus lens onboard that is capable of $2592 \times 1944$ pixel static images. It is connected to the BCM2835 processor on the Raspberry Pi via the Camera Serial Interface (CSI) bus. In addition, the CSI bus is capable of extremely high data rates and it exclusively carries pixel data.

\section{Software}

The ultrasonic sensor has a trigger pin that output digital signal and an echo pin that input digital signal from Arduino Mega. Hence, by using this concept, most exterior railway track defect can be detected. When the railway track is not defective, the ultrasonic sensor should detect a certain distance that is constant along the non-defective railway track. So, that certain distance will be the benchmark distance whereby the railway track is not defective. In the case where the distance detected is more than the benchmark distance, that section of the railway track has a high probability of being defective.

If railway track defect is detected, CARIV will position itself for the camera to capture the defective railway track and remain stationary until the notification is sent. Then, Arduino Mega will prompt Raspberry Pi to capture an image of the defective railway track using PiCamera and the image is saved in the Raspberry Pi. In addition, the GPS coordinate of the defective railway track will be converted to a Google Maps URL. Finally, Raspberry Pi will send the image of the defective railway track together with the Google Maps URL via email. The email is sent using Python's email package which is a library for managing email messages. Hence, the operator can verify the railway track defect and determine the seriousness of the railway track defect. Moreover, the operator can instantly obtain the location of the defective railway track by accessing the Google Maps URL.

Furthermore, a Python script is written to stream live video feedback of the railway track to the web browser using OpenCV and Flask So, the web browser streaming the video can be viewed by entering the IP address of the Raspberry Pi into the web browser. Thus, operators can perform visual inspection on the railway track without having to walk along the railway track.

\section{CONCLUSION}

In conclusion, the finalised design (see Fig. 18) that is faultless will be assembled together after every part are printed. CARIV is able to detect railway track defect and inform railway operators regarding the location and the image of the track defect. So, railway operators should deploy CARIV as their railway inspector to increase the 
efficiency of railway track defects inspection.

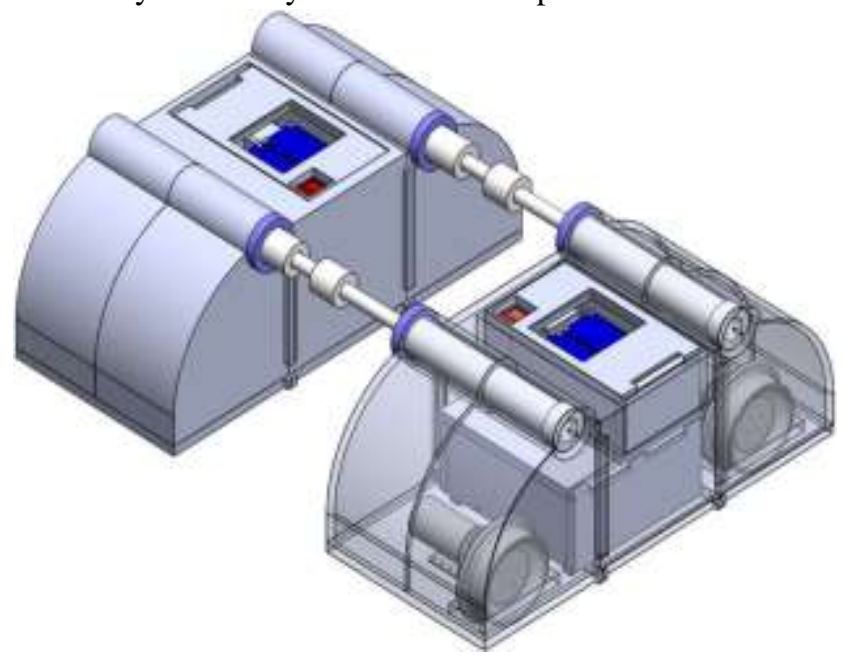

Fig. 18. SolidWorks rendering of CARIV

\section{ACKNOWLEDGMENT}

Authors wish to express our gratitude to honorable university, Universiti Teknikal Malaysia Melaka (UTeM). Special appreciation and gratitude to especially for Centre of Research and Innovation Management (CRIM), Center for Robotics and Industrial Automation (CERIA) for supporting this research and to Faculty of Electrical Engineering from UTeM for supporting this research under PJP (PJP/2019/FKE(3C)/ S01667).

\section{REFERENCES}

1. M. I. M. Masirin, A. M. Salin, A. Zainorabidin, D. Martin, and N. Samsuddin, "Review on Malaysian rail transit operation and management system: Issues and solution in integration," IOP Conf. Ser. Mater. Sci. Eng., 226(1), 2017, pp. 1-7.

2. Ministry of Transport. (2017). Kuala Lumpur urban rail development: Malaysia experience. [Online]. Available: https://www.unescap.org/sites/default/files/17.\%20Devel opment\%20of\%20LRT-\%20Ms.Rosnina.pdf.

3. Land Public Transport Commission. (2017). Annual review 2017. [Online]. Available: https://www.spad.gov.my/sites/default/files/spad-annualreview-2017-en.pdf.

4. M. A. Anis, J. P. Srivastava, N. R. Duhan, and P. K. Sarkar, "Rolling contact fatigue and wear in rail steels: An overview," IOP Conference Series: Materials Science and Engineering, 377(1), 2018, pp. 1-6.

5. X. Giben, V. M. Patel, and R. Chellappa, "Material classification and semantic segmentation of railway track images with deep convolutional neural networks," IEEE International Conference on Image Processing, 2015, pp. 621-625.

6. X. Gibert, V. M. Patel, and R. Chellappa, "Deep multitask learning for railway track inspection," IEEE Trans. Intell. Transp. Syst., 18(1), 2017, pp. 153-164.

7. Office of Railway Safety. (2017). Track and rail and infrastructure integrity compliance manual. [Online]. Available: https://www.fra.dot.gov/Elib/Document/16973.

8. P. Connor. (2017). Track basics. [Online]. Available: http://www.railway-technical.com/infrastructure/trackbasics-v2.pdf.

9. A. Sabato and C. Niezrecki, "Feasibility of digital image correlation for railroad tie inspection and ballast support assessment," Measurement, 103, 2017, pp. 93-105.

10. X. Gibert, V. M. Patel, and R. Chellappa, "Robust fastener detection for autonomous visual railway track inspection," IEEE Winter Conference on Applications of Computer Vision, 2015, pp. 694-701.

11. A. R. Rizvi, P. R. Khan, and S. Ahmad, "Crack detection in railway track using image processing," Int. J. Adv. Res. Ideas Innov. Technol., 3(4), 2017, pp. 489-496.

12. M. Karakose, O. Yaman, M. Baygin, K. Murat, and E. Akin, "A new computer vision based method for rail track detection and fault diagnosis in railways," Int. J. Mech. Eng. Robot. Res., 6(1), 2017, pp. 17-22.

13. A. K. Dubey and Z. A. Jaffery, "Maximally stable extremal region marking-based railway track surface defect sensing,” IEEE Sens. J., 16(24), 2016, pp. 9047 9052.

14. Y. Santur, M. Karaköse, İ. Aydın, and E. Akın, "IMU based adaptive blur removal approach using image processing for railway inspection," International Conference on Systems, Signals and Image Processing, 2016, pp. 1-4.

15. D. O. K. Ming, A. P. T. Seong, and J. Jurit. (2018). What is the future of KTM? [Online]. Available: https://penanginstitute.org/wp-

content/uploads/jml/files/research_papers/What is the future

KTM_OKM_Atticus_12March2018_FINAL_UpdatedQ4 2017.pdf.

16. P. Navaraja, "Crack detection system for railway track by using ultrasonic and PIR sensor," Int. J. Adv. Inf. Sci. Technol., 1, 2014, pp. 126-130.

\section{AUTHORS PROFILE}

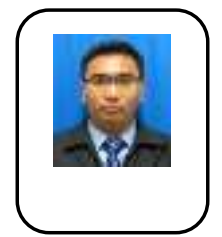

Mohd Bazli Bahar is a lecturer at Faculty of Electrical Engineering, Universiti Teknikal Malaysia Melaka (UTeM). He currently in the field of Mechatronics department. His current research is focusing on robotics control system, Humanoid robot, and His primary interests related to artificial intelligent for autonomous system.

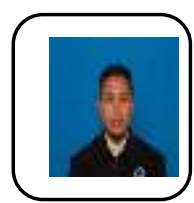

Dr. Mohd Shahrieel Mohd Aras is Associate Professor at Faculty of Electrical Engineering, Universiti Teknikal Malaysia Melaka UTeM. His current research is focusing on control system design of underwater technology. His primary interests related to underwater robotics and Artificial Intelligence.

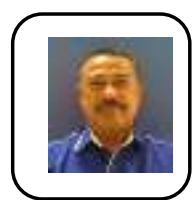

Dr. Marizan Sulaiman is Professor at Faculty of Electrical Engineering, Universiti Teknikal Malaysia Melaka (UTeM), He currently in the field of power and control system. His current research is focusing on power systems and control system.

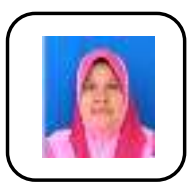

Fadilah Ab Azis is a lecturer at Faculty of Electrica Engineering, Universiti Teknikal Malaysia Melaka (UTeM), He currently in the field of Mechatronicsl department. His current research is focusing on autonomous vehicle and system. 